\title{
DIAGNÓSTICO E PROPOSTA DE INTERVENÇÃO E PREVENÇÃO DO DESEMPENHO PROFISSIONAL DOS COLABORADORES DE UMA EMPRESA: ESTUDO DE CASO METALÚRGICA HERFAB
}

\section{ARTIGO ORIGINAL}

SANTOS, Grazielly Lima dos ${ }^{1}$, BELÉM, Yaçanna Freitas ${ }^{2}$, OLIVEIRA, Daniel Barroso de ${ }^{3}$, ROBERTO, José Carlos Alves ${ }^{4}$

SANTOS, Grazielly Lima dos. Diagnóstico e proposta de intervenção e prevenção do desempenho profissional dos colaboradores de uma empresa: estudo de caso Metalúrgica Herfab. Revista Científica Multidisciplinar Núcleo do Conhecimento. Ano 06, Ed. 05, Vol. 03, pp. 89-110. Maio de 2021. ISSN: 2448-0959, Link de acesso: https://www.nucleodoconhecimento.com.br/administracao/desempenho-profissional, DOI: 10.32749/nucleodoconhecimento.com.br/administracao/desempenhoprofissional

${ }^{1}$ Graduanda do curso de Administração.

${ }^{2}$ Graduando do curso de Administração.

${ }^{3}$ Coorientador. Bacharel em Administração.

${ }^{4}$ Orientador. Mestrado profissional em Engenharia de produção. Especialização em Gestão em Logística empresarial. Graduação em Administração com Ênfase em Marketing.

$\mathrm{RC}: 84492$

Disponível em: https://www.nucleodoconhecimento.com.br/administracao/desempenhoprofissional 


\section{RESUMO}

Atualmente, as empresas e organizações, estão cada vez mais investindo e se preocupando com o desempenho de suas equipes, pois isso influencia diretamente na produtividade e lucros obtidos. Por isso, as ferramentas de gestão devem ser adotadas como uma estratégia de estabelecer metas através do diagnóstico organizacional, tanto com o objetivo de prevenir falhas como reverter. Sendo assim, o investimento na capacitação contínua dos funcionários é essencial para melhorar o desempenho. O objetivo deste artigo é avaliar e diagnosticar o desempenho funcional dos setores da empresa estudada e propor a implementação de programas de treinamento e incentivo para melhorar a eficiência do trabalho dos funcionários. A metodologia utilizada no trabalho, quanto a natureza, foi a forma aplicada, quanto a seus meios, foi feito de forma qualitativa como estudo de caso, e seus fins, foram do tipo exploratório. De acordo com a pesquisa realizada, na primeira etapa do diagnóstico organizacional, constatou-se que a área de recursos humanos é a mais crítica, o que se deve à falta de treinamento e padrões estabelecidos nas funções dos colaboradores, bem como à falta de benefícios e planos de motivação. Por isso, a pesquisa se fundamenta na importância de avaliar o clima organizacional e assim poder traçar estratégias que gerem impactos positivos e em longo prazo a organização. Com o resultado obtido, foi proposto estratégias de treinamento e desenvolvimento para otimizar a produtividade e serviço da metalúrgica em objetivos específicos: descobrir por que os funcionários da empresa não estão entusiasmados, analisar como aumentar a produtividade do restaurante por meio de treinamento e propor incentivos e benefícios para os funcionários planejados. Através das ferramentas mencionadas, para obtenção de melhoria nos processos dos recursos humanos, espera-se que isso monitore as medidas de melhoria e implemente responsabilidades, aumentando a produtividade.

Palavras chave: Recursos Humanos, treinamento, produtividade, motivação.

$\mathrm{RC}: 84492$

Disponível em: https://www.nucleodoconhecimento.com.br/administracao/desempenhoprofissional 


\section{INTRODUÇÃO}

O treinamento e a capacitação são tidos ferramentas essenciais no processo de desenvolvimento organizacional, pois através da aplicação desses métodos é possível prevenir ou intervir em falhas no desempenho de uma organização. Isso se explica, pois o colaborador é o sujeito que possui papel fundamental para o crescimento de uma empresa, sendo assim capacitar de forma contínua os funcionários é forma mais eficaz de garantir uma alta produtividade, redução de erros e custos.

Nesse sentido, a presente pesquisa buscou avaliar o desempenho de diferentes setores de uma empresa do ramo de prestação de serviços, a Metalúrgica Herfab. No estudo foi realizado o diagnóstico organizacional na empresa, que desempenha serviços de colaboração para agilizar o seu negócio através dos seus serviços como: construção de torres, coletores residuais, estruturas metálicas, dutos, tanques, portas de enrolar, fabricação de gancheiras, carrinhos industriais, dispositivos tanques e etc.

Através da avaliação realizada, foi possível obter o diagnóstico, onde foi constatado que determinados setores da organização apresentaram desempenhos baixos, em destaque o setor de recursos humanos, o qual obteve um resultado abaixo do esperado durante a pesquisa realizada em torno das áreas funcionais da organização. A análise também resultou na identificação dos fatores de influência para esse resultado, como a ausência de política de recursos humanos, tão pouco programas de prevenção a acidentes ocupacionais ou um maior investimento em desenvolvimento técnico profissional, além de não estabelecer planos de carreira e promoções.

Através disso, houve um maior direcionamento e preocupação com esse setor, pois o Recursos Humanos $(\mathrm{RH})$ de uma empresa são responsáveis pelo desenvolvimento humano dentro de uma organização. Elas buscam considerar o desenvolvimento dos 
recursos humanos como um fator de importância para o seu crescimento, passando a planejar e realizar capacitação para os seus colaboradores no ambiente de trabalho.

Com isso, houve a necessidade de propor um projeto educacional interno profissionalizante que visa a intervenção e prevenção na capacitação do desenvolvimento dos colaboradores. Com capacitação em liderança, gestão de pessoas, gestão de equipe, desenvolvimento de novas estratégias para o comercial.

Diante disso, o presente estudo tem como objetivo principal estabelecer uma proposta de gestão de recursos humanos, atuando estrategicamente no planejamento, na organização e no desenvolvimento para o cumprimento eficiente e eficaz das atividades e alcance dos objetivos e metas individuais e organizacionais. Além disso, a pesquisa objetiva identificar as melhores práticas de melhoria na do desempenho dos recursos humanos relacionadas ao treinamento e benefícios aos colaboradores; analisar para melhorar a produtividade por meio de treinamento e propor plano de motivação e benefícios; e formular proposta de ações de recursos humanos para melhoria da qualidade de serviços.

Sendo o Recursos Humanos $(\mathrm{RH})$ um dos setores mais importantes na gestão dos colaboradores do circuito completo de uma organização. O estudo justifica-se pelo fato de a falha na otimização dos recursos no setor de $\mathrm{RH}$ pode exercer forte impacto no desempenho de toda a cadeia produtiva de uma empresa. Já que esse setor possui papel fundamental de administrar, planejar, recrutar, selecionar pessoas, e principalmente treinar, objetivando o desenvolvimento das competências individuais coletivas. 


\section{REVISÃO BIBLIOGRÁFICA}

A revisão bibliográfica é a base que sustenta qualquer pesquisa científica. Proporciona o avanço em um campo do conhecimento é preciso primeiro conhecer o que já foi realizado por outros pesquisadores e quais são as fronteiras do conhecimento.

Pereira $(2018$, p.100) afirma que a revisão bibliográfica é uma parte do artigo na qual os resultados obtidos são confrontados com os da revisão e por isso não é interessante colocar autores que não serão utilizados na discussão.

A fundamentação teórica consiste em embasar por meio de ideias de outros autores aspectos teóricos de sua pesquisa. Há diferentes pontos de vista sobre temas em específicos consultados em livros, revistas, artigos, textos, entre outras que mostram o pensamento de diferentes autores e suas ideias sobre os temas, ajudando a dar credibilidade ao trabalho por meio do referencial, o qual deve ser o mais recente possível.

\subsection{O PAPEL DO RECURSOS HUMANOS EM UMA EMPRESA}

De acordo com Steinmetz (2013, p. 14) o recursos humanos $(R H)$ de uma empresa é um setor que possui a responsabilidade de desenvolver e aplicar um conjunto de princípios estratégicos e técnicos que contribui para atrair, manter, motivar, treinar e desenvolver o patrimônio humano de qualquer organização. Sendo o ramo de especialização da ciência da Administração que desenvolve todas as ações que têm como objetivo a integração do trabalhador no contexto da organização e o aumento de sua produtividade.

Para Steinmetz (2013, p. 14) o RH requer necessariamente a conjunção de duas realidades: empresas e pessoas. Isso significa fazer com que a empresa crie um contexto no qual as pessoas se sintam bem, ao mesmo tempo em que faz com que

$\mathrm{RC}: 84492$

Disponível em: https://www.nucleodoconhecimento.com.br/administracao/desempenhoprofissional 
elas agreguem valor ao trabalho que executam, permitindo que a empresa alcance os resultados pretendidos pela sua administração.

De acordo com Marinho et al., (2014) uma boa gestão desse setor e as escolhas ideais dos métodos utilizados são importantes para reforçar a sua cultura organizacional com o objetivo de integrar as necessidades individuais e organizacionais, mostrando como as estruturas burocráticas, estilos de liderança e a organização de trabalho de maneira geral podem ser modificados gerando motivação.

Dada a importância do $\mathrm{RH}$ no desempenho e desenvolvimento dos funcionários, as organizações estão cada vez mais investindo em um ambiente motivacional, de aprendizado e em programas de desempenho. Para assim obter resultados satisfatórios para a organização (MARINHO et al., 2014).

É compreendido que o setor de $\mathrm{RH}$ dentro de uma empresa mostra ser de fundamental importância na busca, recrutamento e desenvolvimento de profissionais de excelência oferecendo todos os recursos que caracterizam este setor. Sendo, a área que exerce grande relevância para o crescimento das empresas, por isso elas precisam de um gestor de rh com total habilidade e capacitação para desenvolver o ciclo de funcionários de forma individual e em equipe.

\subsection{O TREINAMENTO COMO FERRAMENTA IMPORTANTE PARA A MELHORIA NO DESEMPENHO ORGANIZACIONAL}

De acordo com Leite e Lott (2013) treinamento é qualquer atividade realizada para aprender e melhorar a atitude ou habilidades dos colaboradores, para que eles possam se adaptar às suas posições e às mudanças do mercado para atingir seus objetivos é um processo no qual os funcionários devem ensinar ou aprimorar as habilidades necessárias para desempenhar com sucesso suas funções. 
Para Marras (2016), o treinamento possui objetivos específicos e genéricos. Os objetivos específicos são: formação profissional, especialização e reciclagem. $\mathrm{Na}$ formação profissional o treinador recebe um preparo para exercer determinada função. Por sua vez, a especialização visa transmitir conhecimento ao campo ou exercício específico para a melhoria dos resultados.

Isso torna o treinamento uma ferramenta que se aplicada de forma contínua é um forte potencial de estratégias para o conhecimento e aprendizado constante e evolutivo. E tal processo é proporcional à demanda atual em que o mercado atual se encontra, com constantes mudanças. Sendo importante atualizar regularmente os funcionários para que a empresa possa inovar em termos de processo.

No entanto, segundo Madruga (2018) apesar da importância da aplicação de treinamentos, as vantagens adquiridas com esse método isolado pode, em muitos casos, não ser o suficiente. Pois, o conhecimento, habilidade e atitude contidos através da prática contínua pode não estar alinhado com valores individuais. Por isso, a junção de educação profissional e aperfeiçoamento de capacidade e motivações se torna a forma mais segura de capacitação.

Essa junção é conhecida como T\&D (treinamento e desenvolvimento). De acordo com Madruga (2018) o objetivo do Treinamento e desenvolvimento é melhorar ou criar as competências dos colaboradores, estimulando assim o desenvolvimento da empresa. Pode ser administrado em qualquer área e nível da organização por meio de cursos, apresentações ou conferências, e utilizado no planejamento estratégico da empresa para o alcance de metas.

A diferença do T\&D não é apenas ajudar as pessoas a adquirir as habilidades necessárias para seu trabalho e atividades diárias, mas também se preparar para o futuro por meio do desenvolvimento de capacidades. Segundo Portes (2017), a prática do treinamento visa valorizar os recursos humanos e levar o colaborador a oferecer $\mathrm{RC}: 84492$

Disponível em: https://www.nucleodoconhecimento.com.br/administracao/desempenhoprofissional 
desenvolvimento e inovação para a empresa, e afirma que o treinamento auxilia os funcionários a empregarem suas principais habilidades e capacidades para terem o melhor desempenho.

Para motivar um funcionário e equipe a ter um bom desempenho, é necessário investir no aprendizado deste indivíduo, por meio de conhecimentos adquiridos durante a sua trajetória na empresa. A partir de processos de educação continuada e do desenvolvimento da prática, o profissional se torna mais qualificado, potencializando suas competências e habilidades, preparando para assumir novos desafios dentro da organização.

\subsection{PLANO DE BENEFÍCIOS}

De acordo com Chiavenato (2014) os benefícios são aquelas facilidades, conveniências ou vantagens que um colaborador recebe da empresa, no sentido de causar estímulos para que estes se sintam mais motivados. Podendo ser financiados parcialmente ou totalmente pela empresa.

Os benefícios têm como objetivo atender as necessidades particulares dos funcionários, satisfazendo diversos aspectos individuais, econômicos e sociais. Desta forma, a empresa deve definir um plano de benefícios adequado para cada pessoa considerando as tarefas realizadas durante o dia, seu status e a sua participação na sociedade (CHIAVENATO, 2014).

As diferenças salariais dos funcionários ajudam a aprimorar seus talentos na empresa e a mantê-los motivados na organização. Um bom plano de benefícios dentro da organização é a diferenciação, o que ajuda a garantir colaboradores que contribuam para a empresa e apresentem novos talentos.

$\mathrm{RC}: 84492$

Disponível em: https://www.nucleodoconhecimento.com.br/administracao/desempenhoprofissional 
De acordo com Ribeiro (2017) alguns dos benefícios que podem ser oferecido incluem: vale-refeição, vale-combustível, programas de assistência médica e odontológica, aconselhamento nutricional, programas de educação financeira, métodos de exercícios físicos, promoções, recompensas para funcionários que atingirem seus objetivos, horário flexível de trabalho, seguro de vida, ótica e farmácia, despesas com creche, etc.

Esses benefícios não fazem parte do salário do funcionário e devem ser usados de forma estratégica para motivar talentos e reter aqueles que podem exercer uma função na organização.

\subsection{CLIMA ORGANIZACIONAL}

A cultura organizacional ou cultura empresarial ou corporativa, é um conjunto de práticas, valores e comportamentos que refletem em como uma organização guia seus negócios, contratações e o desenvolvimento de seus funcionários (FELTRIN, 2020).

Segundo Feltrin (2020, p. 23) o clima organizacional é o indicador de satisfação dos membros de uma empresa, em relação a diferentes aspectos da cultura ou realidade aparente a organização, tais como: políticas de recursos humanos, modelos de gestão, processo de comunicação interna ou externa, valorização profissional e identificação.

De acordo com Gonçalves e Neto (2017) a cultura é à base de uma empresa e as decisões de negócios e de gestão são tomadas por meio de seu valor, o que leva diretamente ao ambiente organizacional, à produtividade dos funcionários e ao desempenho financeiro. Com uma cultura organizacional bem estruturada, é possível alcançar resultados em diversas áreas, como por exemplo: Atração e retenção de 
talentos, Desenvolvimento dos funcionários, Processos mais ágeis, Clima organizacional, Produtividade e satisfação do cliente.

Ao focar nessa estratégia e buscar a melhoria contínua, o trabalho diário da empresa terá muitos benefícios, tornando os funcionários mais motivados, produtivos, satisfação de clientes e melhor desempenho financeiro. No entanto, é importante lembrar que a missão de garantir a continuidade dessa cultura está em todos os níveis hierárquicos de uma organização. Portanto, de acordo com as necessidades da empresa, o trabalho de fortalecimento contínuo da cultura e adequação do processo não muda.

\subsection{AVALIAÇÃO $360^{\circ}$}

De acordo Chiavenato (2014, p. 215) essa ferramenta possibilita a avaliação de um colaborador mediante as suas competências, habilidades e alinhamento cultural, pelas partes que compõem seu entorno profissional, como pares, gestores, líderes, liderados e clientes. Ou seja, é um tipo de análise realizada em torno de diversas variáveis na atuação profissional, sendo possível a identificação de falhas e ajustes necessários.

Costa e Castro (2016) mostram que o modelo de avaliação $360^{\circ}$ graus exige que a equipe tenha maturidade e conhecimento das ferramentas, pois caso contrário os funcionários serão avaliados por colegas, subordinados, chefes e até mesmo clientes externos da organização, caso contrário ocorrerão conflitos de várias sequências e naturezas. Também deve identificar oportunidades de melhoria em seu plano de ação e proporcionar comodidade aos funcionários para que possam obter o treinamento necessário para que as próprias competências requeridas pela empresa sejam bem executadas. 
Diante disso, entende-se que a implantação adequada de ferramentas de avaliação de desempenho pode trazer benefícios para a organização. Esta ferramenta ajudará a determinar o nível de desenvolvimento dos funcionários, além de dar suporte na criação de um banco de dados para contratação de novos colaboradores.

\section{MATERIAIS E MÉTODOS}

A metodologia pode ser descrita como uma série de procedimentos realizados para desenvolver uma pesquisa que visa responder uma pergunta de investigação. Vale destacar que a disciplina é responsável por produzir ciência e ainda acompanhar o seu modelo de tratamento.

Segundo Trigueiro (2014, p. 30) a metodologia é considerada o estudo de métodos que são aplicados em uma pesquisa científica, podendo ser utilizado diversos meios para a escolha e desenvolvimento de um método específico, sendo essencial para auxiliar os pesquisadores em todo o processo de pesquisa.

\subsection{PROCEDIMENTOS METODOLÓGICOS}

Segundo Severino (2016) os procedimentos metodológicos representam a escolha do método e a forma de pesquisa a ser utilizada que corresponde a todo conjunto de tomada de decisões e ações quanto à escolha das técnicas de pesquisa e método para o desenvolvimento de um trabalho científico. Podendo ser classificados quanto a sua natureza, fins e meios.

Os procedimentos metodológicos desta pesquisa são classificados em: pesquisa aplicada quanto a sua natureza; no que diz respeito aos seus fins ela é exploratória e em relação a sua classificação é estudo de caso. Assim, esse estudo buscou conhecimento acerca do objeto de pesquisa, a fim de propor soluções para os problemas específicos encontrados.

$\mathrm{RC}: 84492$

Disponível em: https://www.nucleodoconhecimento.com.br/administracao/desempenhoprofissional 


\subsubsection{QUANTO A NATUREZA}

O estudo trata-se de uma pesquisa com natureza aplicada, pois é um tipo de método projetado para responder a perguntas específicas destinadas a resolver problemas práticos.

Sendo possível aplicar os instrumentos de estudo na empresa escolhida. Além disso, o resultado e os conhecimentos adquiridos na pesquisa aplicada têm objetivos da elaboração de propostas de implementação de procedimentos ou serviços.

Vergara (2016, p.72) afirma que

a pesquisa aplicada é fundamentalmente motivada pela necessidade de resolver problemas concretos, mais imediatos, ou não. Tem, portanto, finalidade prática, ao contrário da pesquisa pura, motivada basicamente pela curiosidade intelectual do pesquisador e situada sobretudo no nível da especulação.

\subsubsection{QUANTO AOS FINS}

Quanto aos fins, uma pesquisa pode ser exploratória, descritiva, explicativa, metodológica, aplicada e intervencionista. Sendo esse presente estudo com características exploratórias.

Conforme Severino (2017, p.91) diz que: "a pesquisa exploratória busca apenas levantar informações sobre um determinado objeto, delimitando assim um campo de trabalho, mapeando as condições de manifestação desse objeto."

Quanto aos fins, a pesquisa será exploratória para ser mais direto com o objetivo do estudo de caso, e explicativa a fim de conectar as ideias e fatores para solucionar a causa ou fenômeno do problema de forma intervencionista para interferir na realidade estudada a com intuito de modificá- la.

$\mathrm{RC}: 84492$

Disponível em: https://www.nucleodoconhecimento.com.br/administracao/desempenhoprofissional 


\subsubsection{QUANTO AOS MEIOS}

Quanto aos meios foi usado o exploratório, por procurar utilizar a pesquisa na investigação de informações relacionadas a possíveis problemas e suas variáveis, pois é algo que pode não estar claramente definido. Esse tipo de pesquisa contribui para o entendimento do problema existente no ambiente de pesquisa.

Sendo a busca das informações necessárias em fontes secundárias, de modo a coletar os dados para avaliação diretamente com a fonte. Foi identificado os fatores que norteiam a problemática, sendo assim possível a elaboração das estratégias das propostas para solução e prevenção do caso estudado. Carvalho $(2019$, p.44) afirma que "estudo de caso é o tipo de pesquisa cujo procedimento volta-se para um caso específico com o objetivo de conhecer suas causas de modo abrangente e completo."

\subsection{CARACTERIZAÇÃO DA EMPRESA: METALÚRGICA HERFAB}

A Metalúrgica Herfab Eireli, cujo nome fantasia e Metalúrgica Herfab, Rua Manduri (antiga Chico Mendes), 977 - Bairro Zumbi dos Palmares Manaus-AM, no ramo de serviços de manutenção industrial e prestação de serviços, tendo como suas atividades no ramo Fabricação de esquadrias de metal e alumínio, instalações e divisórias, fabricação e montagem de estruturas metálicas e etc. Refere que a empresa está atenta ao mercado com novos serviços conforme o desejo dos clientes e a evolução do mercado, a estrutura atual da empresa conta com vinte colaboradores, considerada uma empresa de médio porte.

Por conta da localização e toda essa variedade de serviços na zona central em que a empresa está localizada, existe um volume muito grande de movimentação de serviços, ou seja, a Metalúrgica Herfab possui os seguintes serviços: Prestadora de serviços de manutenção, existe em função dos anseios de seus colaboradores e das necessidades de seus clientes, tendo como meta a plena satisfação destes. Atuando

$\mathrm{RC}: 84492$

Disponível em: https://www.nucleodoconhecimento.com.br/administracao/desempenhoprofissional 
como agente para a evolução dos negócios, faz da tecnologia uma ferramenta para a racionalização dos processos e consequência vantajosa dos objetivos.

\section{RESULTADOS E DISCUSSÕES}

Com base nos estudos realizados na etapa do Diagnóstico Organizacional, as informações foram coletadas e tabuladas e agrupadas, sendo comparados um a um. Foi apurado que a empresa em estudo possui pontos fundamentais em cada área funcional da organização, como se observa no gráfico 1: Medição de desempenho por setor.

Gráfico 1: Medição de desempenho

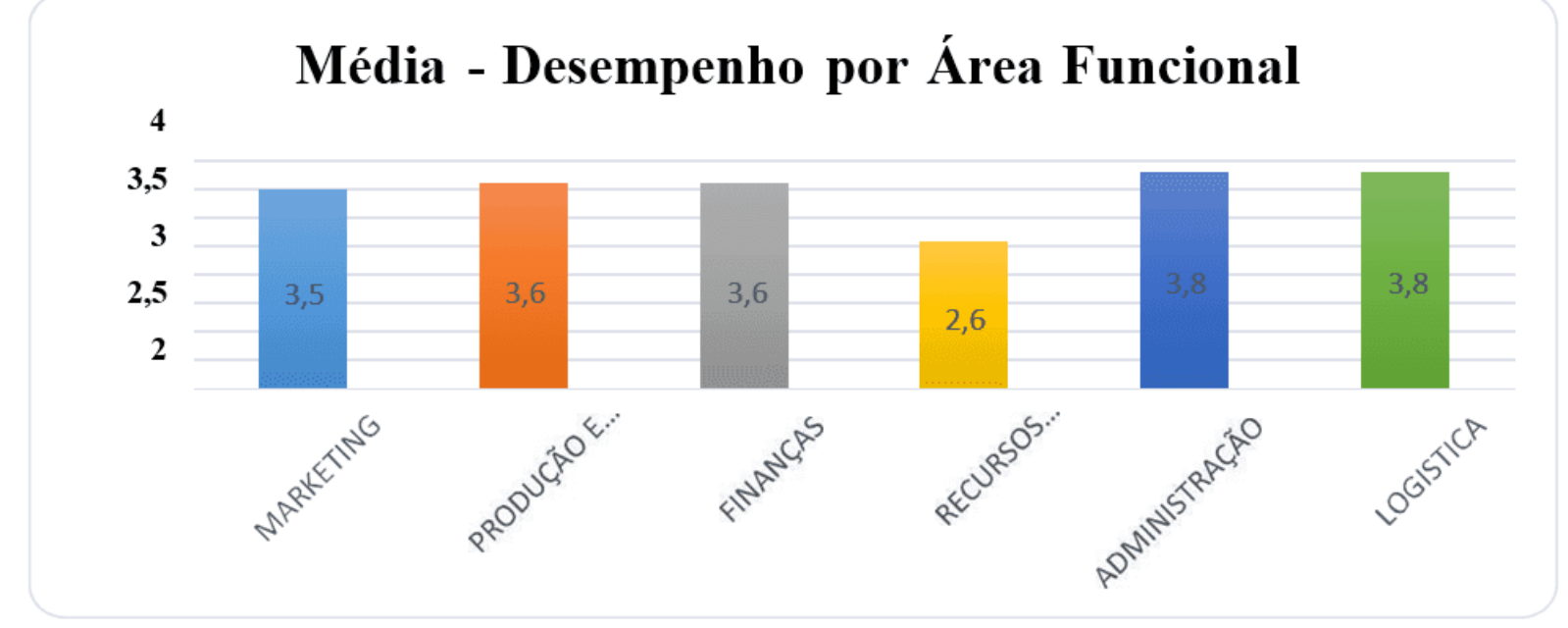

Fonte: Elaborado pelos autores com base na coleta de dados, 2020

De acordo com a análise foi possível traçar o diagnóstico de acordo com a média de avaliação de cada setor da empresa Metalúrgica Herfab. A média de desempenho foi consideravelmente boa nas áreas de desempenho Administração e Logística; já os setores Finanças, Marketing e Produção tiveram o desempenho médio e o setor da 
empresa que teve a menor classificação em relação a funcionalidade foi o Recursos Humanos.

Foi verificado que a empresa não possui prática de aplicação de avaliação para conhecimento do desempenho organizacional dos setores, o que dificulta a compreensão de pontos na cadeia organizacional que podem ter falhas e assim prejudicar em algum momento o processo. Os métodos utilizados para avaliação do desempenho organizacional foram os já mencionados em tópicos anteriores desta pesquisa: Avaliação $360^{\circ}$ e clima organizacional.

De acordo com Austin (2013) o diagnóstico do desempenho de uma empresa é fundamental para que a organização possa agilizar as tomadas de decisões, sendo uma ferramenta que possibilita a visão geral e dinâmica de cada ponto da organização. Sendo assim, a empresa estudada possui, como não realiza o uso desse instrumento de gestão vai de acordo com o resultado obtido que apresenta a deficiência do estabelecimento de um roteiro de plano de ações reparadoras e preventivas.

Como o setor de recursos humanos foi a área da empresa que obteve o pior diagnóstico do desempenho funcional, foi dada uma atenção para avaliação mais específica neste setor, a fim de serem identificadas as variáveis de serviço de forma isolada para melhor esclarecimento. Por isso, os dados coletados foram planilhados e calculados a média de desempenho como é mostrada no Quadro 1, a seguir: 
Quadro 1. Grau de avaliação da área funcional do setor de recursos humanos.

\begin{tabular}{|c|c|c|c|c|c|c|}
\hline \multirow{2}{*}{\multicolumn{2}{|c|}{$\begin{array}{l}\text { AREA FUNCIONAL } \\
\text { RECURSOS HUMANOS }\end{array}$}} & \multicolumn{5}{|c|}{ NIVEL OU GRAU DE AVAUAÇÃO } \\
\hline & & \multirow[t]{2}{*}{ Ponto } & \multirow[t]{2}{*}{ Ponto } & \multirow[t]{2}{*}{ Ponto } & \multirow[t]{2}{*}{ Ponto } & \multirow{2}{*}{$\frac{\text { Ponto }}{X}$} \\
\hline 1 & Mão de obra proporciona "Capacidade técnica operativa" & & & & & \\
\hline 2 & Empresa pela "Formalização das relações trabalhista prevista na legislação vigente" & $\mathrm{X}$ & & & & \\
\hline 3 & Metodologia científica: teoria e aplicação na educação a distância & & $\mathrm{X}$ & & & \\
\hline 4 & Investimento em programas de motivação dos trabalhadores & & & & $\mathrm{X}$ & \\
\hline 5 & Investimento em Desenvolvimento técnico profissional & & & & $\mathrm{X}$ & \\
\hline 6 & Empresa estipula média de horas de formação por trabalhador & & & & $\mathrm{X}$ & \\
\hline 7 & Empresa possui programa de prevenção "Acidente no local do trabalho" & & & $\mathrm{X}$ & & \\
\hline 8 & Possui programa de recrutamento e seleção estruturado & & & & $\mathrm{X}$ & \\
\hline 9 & Taxas de absenteísmo são aceitavéis & & $\mathrm{X}$ & & & \\
\hline 10 & Determinação metas individuais de desempenho para cada colaborador & & & & & $\mathrm{X}$ \\
\hline \multicolumn{2}{|c|}{ TOTAL $(\Sigma)$} & 5 & 8 & 3 & 8 & 2 \\
\hline \multicolumn{2}{|c|}{ MÉDIA POR GRAU (POR COLUNA) } & 0.5 & 0.8 & 0.3 & 0.8 & 0.2 \\
\hline \multicolumn{2}{|c|}{ DESEMPENHO DA ÁREA } & \multicolumn{5}{|c|}{2.6} \\
\hline
\end{tabular}

Fonte: Elaborado pelos autores com base na coleta de dados, 2020.

De acordo com os fatores críticos apontados no Quadro 1, observa-se itens fundamentais na área de Recursos Humanos na Metalúrgica Herfab que são de grande relevância para os serviços prestados, pois seus colaboradores têm necessidade de estarem bem treinados, com padrões estabelecidos e motivados para obtenção de seus resultados.

\subsection{PLANEJAMENTO DE AÇÕES}

Simão; Mendonça e Rodrigues (2018) mostram que o planejamento das ações consiste em uma quantidade de passos de ação ou alterações no modo a se expor o que deve ser implementado. Esse planejamento é ideal para estabelecer melhorias no desempenho e em falhas das equipes, servindo como uma ferramenta de estratégia no alcance de determinadas metas.

Segundo Del Corso et al., (2014) essas estratégias de planejamento podem ser elaboradas pela equipe de $\mathrm{RH}$ da empresa. No entanto, a empresa estudada apresenta maior dificuldade de desempenho justamente nesse setor, o que se torna

RC: 84492

Disponível em: https://www.nucleodoconhecimento.com.br/administracao/desempenhoprofissional 
contraditório mediante a análise obtida. Sendo assim, foi proposto um plano de ações interventivas para o setor de $\mathrm{RH}$, com o objetivo de melhorar a performance e falhas no processo organizacional.

As ações foram estabelecidas de acordo com as maiores deficiências encontradas nesse setor e foram utilizados meios estratégicos de fácil aplicação. Segue abaixo a planilha referente a essa proposta:

Quadro 2: Proposta de ações interventivas para a melhoria no desempenho do $\mathrm{RH}$.

\begin{tabular}{|c|c|c|c|c|}
\hline & Ações Interventivas & Cronologia & Duração & Custo \\
\hline 1 & $\begin{array}{l}\text { Estruturar plano de treinamento para a } \\
\text { padronização na prestação de serviço }\end{array}$ & Março/2021 & 10 dias & $\begin{array}{l}R \$ \\
800,00\end{array}$ \\
\hline 2 & $\begin{array}{l}\text { Implementação do programa de } \\
\text { reconhecimento e oportunidade aos } \\
\text { funcionários. }\end{array}$ & Março/2021 & 8 dias & $\begin{array}{l}\mathrm{R} \$ \\
1.000,00\end{array}$ \\
\hline 3 & $\begin{array}{l}\text { Implementação da pesquisa de clima } \\
\text { organizacional }\end{array}$ & Abril/2021 & 10 dias & $\begin{array}{l}\mathrm{R} \$ \\
600,00\end{array}$ \\
\hline 4 & $\begin{array}{l}\text { Implementação de plano motivação e } \\
\text { benefícios. }\end{array}$ & Maio/2021 & 7 dias & $\begin{array}{l}R \$ \\
500,00\end{array}$ \\
\hline 5 & $\begin{array}{l}\text { Implementação da avaliação } 360^{\circ} \text { para } \\
\text { melhoria contínua dos processos. }\end{array}$ & Abril/2021 & 15 dias & $\begin{array}{l}\mathrm{R} \$ \\
2.000,00\end{array}$ \\
\hline \multicolumn{4}{|c|}{ TOTAL } & $\begin{array}{l}R \$ \\
4.900,00\end{array}$ \\
\hline
\end{tabular}

Fonte: Elaborado pelos autores, 2021.

A proposta remate que cada etapa se desenvolveu por meio de quadros $5 \mathrm{w} 2 \mathrm{~h}$, que é uma ferramenta administrativa que pode ser utilizada em qualquer empresa a fim de

$\mathrm{RC}: 84492$

Disponível em: https://www.nucleodoconhecimento.com.br/administracao/desempenhoprofissional 
registrar de maneira organizada e planejada como serão efetuadas as ações, assim como por quem, quando, onde, porquê, como e quando irá custar para a empresa.

Andrade $(2018$, p. 53) afirma que: $\mathrm{O} 5 \mathrm{~W} 2 \mathrm{H}$ trata-se de uma ferramenta administrativa que pode ser utilizada para registrar de forma organizada, clara e planejada como deverão ser executadas as ações. Esta ferramenta possibilita uma visão ampla dos Planos de Ação.

\subsubsection{PLANO DE TREINAMENTO PARA A PADRONIZAÇÃO NA PRESTAÇÃO DE SERVIÇO}

Para melhoria no desempenho organizacional da empresa, é necessário a aplicação de treinamentos de forma contínua com toda a equipe da empresa e específica para cada setor. O estudo de Guimarães e Pimenta (2020) apresenta que atualmente, mediante as crises econômicas mundiais, as ferramentas de treinamentos são métodos imprescindíveis dentro das organizações, pois a capacitação dos funcionários é a promoção de competências profissionais para as atividades praticadas.

A empresa objeto de estudo da atual pesquisa não apresentou planos de treinamentos contínuos com os funcionários, o que mostra o despreparo do setor de recursos humanos nas habilidades de gestão organizacional, sendo um dos papéis mais importantes do $\mathrm{RH}$ na cadeia de desenvolvimento profissional e pessoal da empresa.

Por isso, foi elaborada uma proposta de plano de treinamento para que a equipe de recursos humanos possa se organizar e estabelecer e disseminar o plano para outros setores.

RC: 84492

Disponível em: https://www.nucleodoconhecimento.com.br/administracao/desempenhoprofissional 
Quadro 3: Plano de treinamento para a padronização na prestação de serviço.

\section{Estruturar plano de treinamento para a padronização na prestação de serviço}

O quê? Plano de treinamento.

Por quê? Para a padronização na prestação de serviço.

Onde? Metalúrgica Herfab.

Quando? Terceira semana de Abril de 2021.

Quem? Departamento de produção.

Como? Através de reunião para definir como serão desenvolvidos os processos e mediante a treinamento e corrigir possíveis gargalos.

Quanto? R\$800,00

Fonte: Elaborado pelos autores, 2021.

\subsubsection{IMPLEMENTAÇÃO DO PROGRAMA DE RECONHECIMENTO E OPORTUNIDADE AOS FUNCIONÁRIOS}

Ribeiro e Santana (2015) essas ações são fundamentais em uma empresa, pois o funcionário passa a se sentir valorizado, de certa forma e isso contribui para o melhor desempenho, pois eleva a força de vontade e assim a produtividade e qualidades de serviço aumentam.

O reconhecimento dos funcionários pode ser estabelecido pela elevação do funcionário destaque por mês, com premiações de canecas personalizadas da empresa, camisetas e vale- presentes. Outro aspecto importante que a empresa pode utilizar é a cultura de feedback.

Pois, de acordo com Almeida (2013) a comunicação interna na organizacional é fundamental para esclarecimento de problemas e dificuldades encontrados nos RC: 84492

Disponível em: https://www.nucleodoconhecimento.com.br/administracao/desempenhoprofissional 
processos e atividades, sendo altamente uma ferramenta para auxiliar na melhoria do desempenho dos funcionários.

Isso possibilita que os colaboradores se tornem mais confiantes na continuidade de suas funções, o que ajuda a coordenar as estratégias corporativas. Aumentando a organização e melhor colaboração entre as equipes, o que impacta positivamente nos resultados individuais e coletivos.

Quadro 4: Implementação do Programa de reconhecimento e oportunidade aos funcionários.

\begin{tabular}{|c|c|}
\hline O quê? & Programa de reconhecimento e oportunidade aos funcionários. \\
\hline Por quê? & Para reconhecimento e oportunidade aos funcionários. \\
\hline Onde? & Metalúrgica Herfab. \\
\hline Quando? & Quarta semana de Março de 2021. \\
\hline Quem? & Todos os colaboradores da empresa \\
\hline Como? & $\begin{array}{l}\text { Formulando medidas organizacionais e de gestão para recompensar os } \\
\text { funcionários. }\end{array}$ \\
\hline Quanto? & $\mathrm{R} \$ 1.000,00$ \\
\hline
\end{tabular}

Fonte: Elaborado pelos autores, 2021.

\subsubsection{IMPLEMENTAÇÃO DA PESQUISA DE CLIMA ORGANIZACIONAL}

$\mathrm{Na}$ avaliação realizada foi possível diagnosticar e analisar o clima organizacional da empresa, o que permitiu avaliar e medir a forma como cada colaborador desempenha as suas funções de forma objetiva e sistemática, propondo medidas de melhoria do

RC: 84492

Disponível em: https://www.nucleodoconhecimento.com.br/administracao/desempenhoprofissional 
ambiente de trabalho. De acordo com o diagrama de relacionamento estabelecido, o processo de implantação da organização da pesquisa de clima é dividido em cinco etapas, em que a área de recursos humanos inicia a implantação do plano de melhorias.

Etapa 01: Organizar um plano de pesquisa de clima.

Etapa 02: Preenchimento do questionário.

Etapa 03: Análise dos Resultados do Questionário.

Etapa 04: Proposta de ações.

Etapa 05: Etapa de feedback aos participantes.

Quadro 5: Implementação da pesquisa de clima organizacional.

\section{Implementação da pesquisa de Clima Organizacional}

\begin{tabular}{l|l|}
\hline O quê? & Implementação da pesquisa de Clima Organizacional. \\
\hline Por quê? & $\begin{array}{l}\text { Para medir a forma como cada colaborador desempenha as suas } \\
\text { funções. }\end{array}$ \\
\hline Onde? & Metalúrgica Herfab. \\
\hline Quando? & Primeira semana de Abril de 2021. \\
\hline Quem? & Todos os colaboradores da empresa. \\
\hline Como? & A pesquisa será realizada em 5 etapas. \\
\hline Quanto? & $\mathrm{R} \$ 600,00$
\end{tabular}

Fonte: Elaborado pelos autores,2021.

O clima organizacional é importante mediante a uma estratégia de gestão, que permite uma análise dos procedimentos internos e externos, sendo possível diagnosticar a

$\mathrm{RC}: 84492$

Disponível em: https://www.nucleodoconhecimento.com.br/administracao/desempenhoprofissional 
avaliação e o comprometimento dos funcionários com as metas estabelecidas pela empresa (ANDRADE; FISCHER; STEFANO, 2015).

O que torna uma proposta de estratégia de prevenção e correção de falhas essencial para a empresa estudada, pois foi detectado na análise a ausência de estratégias e ações, o que impede o maior crescimento e desenvolvimento da organização.

\subsubsection{IMPLEMENTAÇÃO DE PLANO DE MOTIVAÇÃO E BENEFÍCIOS}

De acordo com o estudo de Carvalho et al., (2013) os benefícios direcionados aos colaboradores geram grande impacto na motivação dos mesmo. Por isso, a proposta de um plano de plano de benefícios inclui a gestão dos benefícios proporcionados aos colaboradores da empresa, pois o funcionário quando bem motivado, organizado e utilizado, constitui o diferencial de valor acrescentado e motivação.

Para atingir as metas estabelecidas, concluir os serviços no prazo e melhorar continuamente a qualidade, a organização precisa manter o entusiasmo e a dedicação dos funcionários, a lealdade e a satisfação. Por este motivo, a implementação de um plano motivacional e benefícios pode fazer com que a equipe se motive e mantenha um baixo índice de rotatividade, além de ser propícia ao clima organizacional, além de propiciar o desenvolvimento da empresa e dos colaboradores.

Quadro 6: Implementação de plana motivação e benefícios.

\section{Implementação de plano motivação e benefícios}

O quê? Implementação de plano motivação e benefícios.

Por quê? Para motivação dos colaboradores, aumenta o rendimento e melhora o clima organizacional.

Onde? Metalúrgica Herfab.

Quando? Terceira semana de Maio de 2021.

$\mathrm{RC}: 84492$

Disponível em: https://www.nucleodoconhecimento.com.br/administracao/desempenhoprofissional 
Quem? Todos os colaboradores da empresa.

Como? Através da elaboração de Plano de Recompensa.

Quanto? R\$500,00

Fonte: Elaborado pelos autores, 2021.

Manter a equipe motivaa, pode trazer diversos benefícios, que vão desde a eficácia do processo, a qualidade, e também a economia com pessoal, evitando assim a rotatividade de funcionários, resultando numa equipe cada vez mais introzada.

Assim, identificar O quê fazer, é passo inicial para qualquer plano,o por quê fazer, esclarece o camiho para alcançar o objetivo, o Onde fazer é item básico de identificação, mas que precisa estar claro num planejamento, o Quando fazer é importante para delimitar tempo de início, meio e fim, o Quem, identifica as pessoas ou colaboradores que irão participar daquele projeto, o Como, é a forma que irá ser executada aquela ação, e o Quanto, refere-se aos custos.

\subsubsection{IMPLEMENTAÇÃO DA AVALIAÇÃO 360 PARA MELHORIA CONTÍNUA DOS PROCESSOS.}

A proposta de implementação dessa ferramenta para avaliação de desempenho, o método proposto baseia-se na necessidade da empresa em identificar, manter e adquirir profissionais qualificados no âmbito desta atividade, pois a organização se encontra em fase de crescimento e carece de profissionais qualificados na região.

Ao realizar essa pesquisa, é possível observar o conhecimento do funcionário sobre o assunto, para que possa definir o método mais adequado de implementação da ferramenta de avaliação de desempenho. Por isso, foi elaborado uma planilha com a proposta mais adequada de acordo com a necessidade da metalúrgica, segue abaixo:

RC: 84492

Disponível em: https://www.nucleodoconhecimento.com.br/administracao/desempenhoprofissional 
Quadro 6: Implementação da avaliação $360^{\circ}$ para melhoria contínua dos processos

\section{Implementação da avaliação $360^{\circ}$ para melhoria contínua dos processos.}

\begin{tabular}{|l|l|}
\hline O quê? & Avaliação $360^{\circ}$ para melhoria contínua dos processos. \\
\hline Por quê? & $\begin{array}{l}\text { Necessidade da empresa em identificar, manter e adquirir profissionais } \\
\text { qualificados no âmbito desta atividade. }\end{array}$ \\
\hline Onde? & Metalúrgica Herfab. \\
\hline Quando? & Quarta semana de Abril de 2021. \\
\hline Quem? & Todos os colaboradores da empresa. \\
\hline Como? & Aplicando a avaliação $360^{\circ}$ \\
\hline Quanto? & $\mathrm{R} \$ 2.000,00$ \\
\hline
\end{tabular}

Fonte: Elaborado pelos autores, 2021.

De acordo Chiavenato $(2014$, p. 215$)$ a avaliação $360^{\circ}$ é um método relativamente moderno de avaliação de desempenho que se diferencia dos métodos tradicionais, principalmente porque a avaliação é realizada por todos os elementos que mantêm uma certa interação com o avaliador, a saber, disse que não é apenas o líder direto do trabalhador, mas também seus colegas, subordinados, clientes e até mesmo ele próprio.

O que torna uma ferramenta de importante uso para a empresa de estudo, visto que o diagnóstico de pior desempenho foi o do setor de recursos humanos, o que mostra o despreparo do gestor na aplicação e elaboração de estratégias para melhoria e desenvolvimento gerais.

\section{CONSIDERAÇÕES FINAIS}

Com o alcance do estabelecimento do objetivo principal do projeto sobre a identificação e elaboração de uma proposta de intervenção e prevenção para o RC: 84492

Disponível em: https://www.nucleodoconhecimento.com.br/administracao/desempenhoprofissional 
diagnóstico avaliado da empresa Metalúrgica Herfab foi alcançada. Pois o intuito da pesquisa foi coletar os dados de desempenho de cada setor, realizar a comparação e obter um resultado que influenciou diretamente a forma como foi criada e seguida as propostas de implantação de desenvolvimento e treinamentos aos colaboradores.

Além disso, o entendimento e esclarecimento da essencialidade que as organizações possuem em estabelecer formas de se diferenciar das demais organizações do mercado, portanto, a implantação de ferramentas para melhoria dos recursos humanos é fundamental para esse objetivo. Visto que o mercado atual está cada vez mais competitivo, surgindo assim as necessidades de alcançar cada vez mais as demandas dos clientes.

Por isso, é necessário que os colaboradores e a empresa estejam alinhados de forma que a comunicação interna seja uma prática ativa e diária. Possibilitando uma perspectiva global sobre todos os aspectos da organização e do departamento, para que possam melhorar continuamente, superar as expectativas dos clientes e sobreviver no mercado.

Nesse sentido, em sua primeira fase, o presente trabalho busca apresentar ferramentas que auxiliam na obtenção dos resultados e melhorias nos desenvolvimentos dos colaboradores. Havendo a necessidade de aplicação e investimento no setor de Recursos humanos, sendo incluso na participação de toda capacitação e desenvolvimento proposto o gestor responsável.

Sendo assim, com o treinamento e desenvolvimento adequado a equipe do $\mathrm{RH}$ será motivada para o desempenho pleno de suas funções, podendo assim disseminar possíveis novas estratégias e inclusão de outras ferramentas de gestão para aplicação contínua nos demais setores da empresa, o que afeta diretamente o nível dos funcionários e sua própria produtividade.

$\mathrm{RC}: 84492$

Disponível em: https://www.nucleodoconhecimento.com.br/administracao/desempenhoprofissional 
Além disto, recomenda-se uma pesquisa específica após a implementação das melhorias propostas neste estudo, para assim fazer comparativos de recursos, resultados, qualidade, dentre outros aspectos que envolvam o projeto.

\section{REFERÊNCIAS}

ALMEIDA, Luís António Santos. A importância da Comunicação Interna para a Motivação dosColaboradores. Exedra: Revista Científica, n. 8, p. 91-103, 2013.

ANDRADE, Darly Fernando Andrade. Gestão pela Qualidade - Volume 3 - Editora Poisson - Belo Horizonte - MG: Poisson, 2018.

ANDRADE, Sandra Mara; FISCHER, André Luiz; STEFANO, Silvio Roberto. Confiança organizacional e interpessoal como uma dimensão de clima organizacional. Revista Base (Administração e Contabilidade) da UNISINOS, v. 12, n. 2, p. 155166, 2015.

AUSTIN, Robert D. Measuring and managing performance in organizations. Addison- Wesley, 2013.

CARVALHO, Luis Osete Ribeiro. DUARTE, Francisco Ricardo. MENEZES, Afonso Henrique Novaes. SOUZA Tito Eugênio Santos. Metodologia científica: teoria e aplicação na educação a distância / [et al.]. - Petrolina-PE, 2019.

CARVALHO, Maria Balbina et al. O papel dos benefícios e incentivos na satisfação do colaborador e nas estratégias das empresas. Caderno de Graduação-Ciências Humanas e Sociais-UNIT-SERGIPE, v. 1, n. 3, p. 31-44, 2013.

CHIAVENATO, Idalberto Gestão de pessoas: o novo papel dos recursos humanos nas organizações / Idalberto Chiavenato. -- 4. ed. -- Barueri, SP: Manole, 2014.

$\mathrm{RC}: 84492$

Disponível em: https://www.nucleodoconhecimento.com.br/administracao/desempenhoprofissional 
COSTA, Stella; CASTRO, Denise. Avaliação de desempenho por múltiplas fontes: um estudo sobre os conceitos intrínsecos ao modelo. In: XII CONGRESSO NACIONAL DE EXCELÊNCIA EM GESTÃO \& III INOVARSE. 2016.

DEL CORSO, Jansen Maia et al. Gestão estratégica de recursos humanos: identificando o processo de alinhamento estratégico. Tourism \& Management Studies, v. 10, n. 1, p. 49-57, 2014.

FELTRIN, Carolina Marques de Almeida. Cultura e clima organizacional - Editora Contentus- Curitiba .2020.

GONÇALVES, Carlos Alberto; GONÇALVES FILHO, Cid; NETO, Mário Teixeira Reis. Estratégiaempresarial. Saraiva Educação SA, 2017.

GUIMARÃES, Ronaldo Maciel; PIMENTA, Cleuza Lúcia. O mundo mudou: a importância do treinamento no momento de crise. CASOTECA Edição Especial: Os impactos da Pandemia no Segmentos do Comércio de Bens, Serviços e Turismo (ISSN: 2675-4703), v. 2, n. 2, 2020.

LEITE, Paula AR; LOTT, Tereza CC. Treinamento e desenvolvimento organizacional, uma ferramenta nasempresas atuais. Revista Científica Semana Acadêmica. Fortaleza, v. 42, n. 1, 2013.

MADRUGA, Roberto. Treinamento e desenvolvimento com foco em educação corporativa. SaraivaEducação SA, 2018.

MARINHO, C. R. P.; MARINHO, R. C. P.; CARVALHO, C. A. S.; GUTIERREZ, R. H. Competência e Aprendizagem: Perspectivas Estratégicas orientadas à vantagem competitiva sustentável.X Ceneg - Congresso Nacional de Excelência em Gestão, ago. 2014.

RC: 84492

Disponível em: https://www.nucleodoconhecimento.com.br/administracao/desempenhoprofissional 
MARRAS, Jean Pierre.Administração de recursos humanos do operacional ao estratégico/Jean PierreMarras. - 15.ed.- São Paulo: Saraiva , 2016.

PEREIRA, Adriana Soares Pereira. Metodologia da pesquisa científica.et al. - 1 . ed. - Santa Maria, RS:UFSM, NTE, 2018.

PORTES, Jose Luiz. O treinamento de pessoal nas organizações.2017. Disponível em:http://www.administradores.com.br/artigos/academico/o-treinamento-de-pessoalnas- organizações/1064265/.Acesso em 16 março.2020.

RIBEIRO, Antonio de Lima. Gestão de pessoas. Saraiva Educação SA, 2017.

RIBEIRO, Larissa Alves; SANTANA, Lídia Chagas de. Qualidade de vida no trabalho: fator decisivo para o sucesso organizacional. Revista de Iniciação Científica-RIC Cairu, v. 2, n. 02, p. 75-96, 2015.

SEVERINO, Joaquim Antônio. Metodologia do trabalho cientifico - $24^{a}$ Ed - São Paulo. Ed:Cortez, 2016.

SEVERINO, Antônio Joaquim . Metodologia do trabalho científico [livro eletrônico] - 2. ed.- São Paulo: Cortez, 2017.

SEVERINO, Antônio Joaquim, 1941 - Metodologia do trabalho científico [livro eletrônico] SIMÃO, André Assaid; MENDONÇA, Denner; RODRIGUES, Dario Geraldo. Aplicação das FerramentasAdministrativas na Gestão Empresarial. Revista da META, 2018.

STEINMETZ, Edeuzane de F.P.S. Administração de Recursos Humanos - Editora NT - Brasilia. 2013. 
TRIGUEIRO, Rodrigo de Menezes; Rodrigo de Menezes Trigueiro, Marilucia Ricieri, Gisleine Bartolomei Fregoneze, Joacy M. Botelho. Metodologia científica - Londrina: Editora e Distribuidora Educacional S.A., 2014.

VERGARA, Sylvia Constant. Projetos e relatórios de pesquisa em administração / Sylvia Constant Vergara.- 16. ed. - São Paulo: Atlas, 2016.

Enviado: Abril, 2021.

Aprovado: Maio, 2021. 